\title{
Research on the Evaluation Method of Cognitive Electronic Equipment Information Acquisition Ability
}

\author{
Xinhai Liu, Yanheng Ma and Zijian Zong \\ UAV Engineering Department, Ordnance Engineering College, Shijiazhuang 050003, China, \\ 568657132@qq.com
} Keywords: Cognitive testability; Index system; Information acquisition ability; Entropy weight
method.

\begin{abstract}
Cognitive testability is an inherent attribute of the modern electronic equipment. The information acquisition ability of cognitive testability was described in details and an evaluation model was built upon the basic construction of the index system of the cognitive testability. First of all, the idea and contents of the information acquisition ability of the modern electronic equipment was stated. Second, based on this, a mathematical model of weight calculation with the use of entropy weight method was built. The innovation and characteristic of this paper lie in the detailed explanation of information acquisition ability and the building of the evaluation model.
\end{abstract}

\section{Introduction}

The concept of cognitive testability and the design of cognitive testability are introduced for forecast the fault of modern electronic equipment. Cognitive testability is a design characteristic [1] that a product can sense its state (workable, non-workable, or performance degradation degree) timely and accurately, forecast its state change tendency and internal failure occurrence probability, and provide a coping strategy, which is a new idea for the future intelligent equipment. It includes state monitoring and failure forecast in the design stage for implementation. That is to say, strict requirements are put forward for state monitoring and failure forecast at the design stage. In the future, the intelligent equipment will have strong information processing ability. With respect to the guarantee of future intelligent equipment, state monitoring, failure diagnosis, failure forecast, and intelligent decision making shall be made based on the large volume of relevant equipment information. Therefore, information acquisition ability is deemed as one important index for the evaluation of cognitive testability and a calculation method shall be provided in index system of cognitive testability. In this Paper, the idea and contents of the information acquisition ability of cognitive electronic equipment was stated, an evaluation model was built, and a calculation method for information acquisition ability was provided.

\section{The Idea and Contents of Information Acquisition Ability}

The information acquisition ability of the modern electronic equipment shall be the ability to acquire multi-source, multi-parameter and multi-sensor information, and historical and experience information, and the ability to make information fusion. In the index system of cognitive testability, the information acquisition ability is described in two aspects: historical information completeness and equipment information completeness with respect to the amount of acquired information; information fusion ability with respect to the quality of acquired information. This can be used to measure the comprehensiveness and quality of the acquired information, and whether the information can provide powerful support for failure diagnosis, failure forecast, and decision making. The historical information completeness includes historical information acquisition completeness of state monitoring, historical information acquisition completeness of failure and maintenance, and historical information acquisition completeness of use environment of the same type of equipment. The purpose of acquiring historical information is to provide information support for failure diagnosis and forecast. Failure characteristic information and sign of failures can be acquired from the large amount of historical state, failure, and maintenance information of the same type of equipment. The 
working environment of the equipment shall be first considered in advanced. Only the analysis of historical data of the same type of equipment under the same or similar environment is meaningful. The equipment information completeness includes state monitoring information acquisition completeness, experience information acquisition completeness, and use environment information acquisition completeness of the equipment. The purpose of acquiring equipment information is to match the historical information so as to implement failure forecast. Information fusion ability includes information relevancy and information sufficiency. Information relevancy describes the relevancy between historical information and equipment information. As the relevancy is greater, the equipment state, failure type, failure tendency, and failure time, etc. estimated with the use of historical information will be more accurate. Information sufficiency describes the sufficiency of the acquired information sample. As the number of acquired samples is larger, the relevancy will be greater, information fusion ability will be stronger, and the judgment on equipment state information will be more accurate.

Table. 1 [1] Information Acquisition Ability of Index System of Cognitive Testability

\begin{tabular}{|c|c|c|c|}
\hline $\begin{array}{l}\text { General target } \\
\text { layer }\end{array}$ & $\begin{array}{c}\text { First-class index } \\
\text { level }\end{array}$ & $\begin{array}{c}\text { Second-class index } \\
\text { level }\end{array}$ & Third-class index level \\
\hline \multirow{12}{*}{$\begin{array}{l}\text { Index system of } \\
\text { cognitive } \\
\text { testability }\end{array}$} & \multirow{8}{*}{$\begin{array}{l}\text { Information } \\
\text { acquisition } \\
\text { ability }(A)\end{array}$} & \multirow{3}{*}{$\begin{array}{l}\text { Historical information } \\
\text { completeness }\left(B_{1}\right)\end{array}$} & $\begin{array}{c}\text { Historical information acquisition completeness of } \\
\text { state monitoring of the same type of } \\
\text { equipment }\left(C_{1}\right)\end{array}$ \\
\hline & & & $\begin{array}{l}\text { Historical information acquisition completeness of } \\
\text { failure and maintenance of the same type of } \\
\text { equipment }\left(C_{2}\right)\end{array}$ \\
\hline & & & $\begin{array}{l}\text { Historical information acquisition completeness of } \\
\text { use environment of the same type of } \\
\text { equipment }\left(C_{3}\right)\end{array}$ \\
\hline & & \multirow{3}{*}{$\begin{array}{l}\text { Equipment information } \\
\text { completeness }\left(B_{2}\right)\end{array}$} & $\begin{array}{l}\text { State monitoring information acquisition } \\
\text { completeness of equipment }\left(C_{4}\right)\end{array}$ \\
\hline & & & $\begin{array}{l}\text { Experience information acquisition completeness } \\
\text { of equipment }\left(C_{5}\right)\end{array}$ \\
\hline & & & $\begin{array}{l}\text { Use environment information acquisition } \\
\text { completeness of equipment }\left(C_{6}\right)\end{array}$ \\
\hline & & \multirow{2}{*}{$\begin{array}{l}\text { Information fusion } \\
\qquad \text { ability }\left(B_{3}\right)\end{array}$} & Information relevancy $\left(C_{7}\right)$ \\
\hline & & & Information sufficiency $\left(C_{8}\right)$ \\
\hline & \multirow{4}{*}{$\cdots$} & \multirow{2}{*}{$\begin{array}{l}\cdots \\
\cdots\end{array}$} & $\ldots$ \\
\hline & & & $\ldots$ \\
\hline & & \multirow{2}{*}{$\begin{array}{l}\cdots \\
\cdots\end{array}$} & $\ldots$ \\
\hline & & & $\ldots$ \\
\hline
\end{tabular}

\section{Evaluation Model of Information Acquisition Ability}

The evaluation model of information acquisition ability can be built in combination

With the index system of cognitive testability. Information acquisition ability $(A)$ is the function of historical information completeness $\left(B_{1}\right)$, equipment information completeness $\left(B_{2}\right)$, and information fusion ability $\left(B_{3}\right)$, as shown in the following formula, $A=B_{1} \square B_{2} \square B_{3}, B_{1}=W_{C_{1}} C_{1}+W_{C_{2}} C_{2}+W_{C_{3}} C_{3}$, in which $B_{1}$ is historical information 
completeness, $C_{1}$ is the historical information acquisition completeness of state monitoring of the same type of equipment, $C_{2}$ is the historical information acquisition completeness of failure and maintenance of the same type of equipment, $C_{3}$ is historical information acquisition completeness of use environment of the same type of equipment, $W_{C_{1}}, W_{C_{2}}$, and $W_{C_{3}}$ are weights of $C_{1}, C_{2}$, and $C_{3}$ respectively; $B_{2}=W_{C_{4}} C_{4}+W_{C_{5}} C_{5}+W_{C_{6}} C_{6}$, in which $\mathrm{B}_{2}$ is equipment information completeness, $C_{4}$ is state monitoring information acquisition completeness of equipment, $C_{5}$ is experience information completeness of equipment, and $C_{6}$ is use environment information acquisition completeness of equipment, ${ }^{C_{4}}, W_{C_{5}}$, and $W_{C_{6}}$ are weights of $C_{4}, C_{5}$, and $C_{6}$ respectively; $B_{3}=C_{7} \complement_{8}$, in which $B_{3}$ is information fusion ability, $C_{7}$ is information relevancy, and $C_{8}$ is information sufficiency; $C_{1}=\sum_{i=1}^{n_{1}} w_{D_{1 i}} \square D_{1 i}$, in which $w_{D_{1 i}}$ and $D_{1 i}$ are respectively the weight and index values of historical information value of state monitoring of the same type of equipment, $i$ is the $i$ performance parameter of the same type of equipment, $i=1,2,3, \cdots, n_{1}$. $C_{2}=\sum_{i=1}^{n_{2}} w_{D_{2 i}} \square D_{2 i}$

, in which $w_{D_{2 i}}$ and $D_{2 i}$ are respectively the weight and index values of historical information value of failure and maintenance of the same type of equipment, $i$ is the $i$ failure and maintenance record of the same type of equipment, $i=1,2,3, \cdots, n_{2} ; C_{3}=\sum_{i=1}^{n_{3}} w_{D_{3 i}} D_{3 i}$, in which $w_{D_{3 i}}$ and $D_{3 i}$ are respectively the weight and index values of historical information values of use environment of the same type of equipment, $i$ is the $i$ environment information of use environment of the same type of equipment, $i=1,2,3, \cdots, n_{3} ; C_{4}=\sum_{i=1}^{n_{4}} w_{D_{4 i}} D_{4 i}$, in which $w_{D_{4 i}}$ and $D_{4 i}$ are respectively the weight and index values of equipment state monitoring information value, $i$ is the $i$ performance parameter of the equipment state monitoring information, $i=1,2,3, \cdots, n_{4}$; $C_{5}=\sum_{i=1}^{n_{5}} w_{D_{5 i}} \square D_{5 i}$, in which $w_{D_{5 i}}$ and $D_{5 i}$ are respectively weight and index values of equipment experience information, $i$ is the $i$ experience information of equipment, $i=1,2,3, \cdots, n_{5}$. $C_{6}=\sum_{i=1}^{n_{6}} w_{D_{6 i}} \square D_{6 i}$

, in which $w_{D_{6 i}}$ and $D_{6 i}$ are respectively weight and index values of equipment use environment information value, $i$ is the $i$ environment information of equipment use environment, $i=1,2,3, \cdots, n_{6} ; C_{7}=D_{7} \square \mathrm{D}_{8}$, in which $D_{7}$ is environment information similarity and $\mathrm{D}_{8}$ are equipment state information similarity; $C_{8}=D_{9} \square \mathrm{D}_{10}$, in which $D_{9}$ is environment information sufficiency and $\mathrm{D}_{10}$ is equipment state information sufficiency; $D_{j i}=\left\{\begin{array}{ll}1, & \text { The } \mathrm{i} \text { index can be acquired } \\ 0, & \text { The } \mathrm{i} \text { index is not acquired }\end{array}, j=1,2,3,4,5,6 ; \quad D_{j}=\frac{\alpha}{n_{7}} \sum_{i=1}^{n_{7}}\left(1-\left|\frac{H_{i}-N_{i}}{H_{i}}\right|\right), j=7,8\right.$, in which $\alpha$ is generally $1, H_{i}$ is the $i$ element of historical information sequence (including historical information and historical environment information of the same type of equipment), e.g. 
$H_{i}$ represents the environment temperature for the same type of equipment to operate at some point); $N_{i}$ is the $i$ element of equipment information sequence (including equipment state information and environment information), e.g. $N_{i}$ represents current value of equipment at one unit at some point; $n_{7}$ is the number of elements of equipment information sequence;

$$
D_{j}= \begin{cases}0 & 0 \leq u \leq a \\ {\left[1+\left(\frac{u-a}{b}\right)^{-2}\right]^{-1} \quad a<u \leq f \quad, j=9,10, \text { in which } u \text { is the number of elements of }}\end{cases}
$$

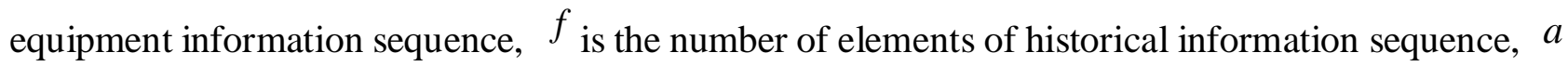
is generally within $0.01 f \square 0.03 f, b$ is generally within $0.1(f-a) . D_{j}$ can be given through expert experience according to the values of $u+1$ and $f$.

The result of information acquisition ability can be obtained through calculation via the afore-said formula after the corresponding values of indexes are substituted into the afore-said formula. The determination of index weight is shown in next section.

\section{Calculating Weight by the Use of Entropy Weight Method}

The index system of cognitive testability is characterized with information flow and big data. Take information acquisition ability as an example, with respect to equipment failure forecast and intelligent decision making, the acquisition of historical information of state monitoring of the same type of equipment, historical information of failure and maintenance of the same type of equipment, historical information of use environment of the same type of equipment, equipment state monitoring information, equipment experience information, and equipment use environment information, etc. will cause a large amount of information and invalid information. The weights of indexes at all levels shall be first determined when the index system modeling of cognitive testability is conducted.

A weight shall mean the share and importance of an element in the entire system, and the impact on the evaluated target. As the weight is greater, the importance will be relevantly greater, vice versa [3].

In order to scientifically evaluate indexes in the index system of cognitive testability and avoid the use of the subjective method for determination of index weight, the entropy weight method is applied in this Paper to determine the weights of different indexes and a weight decision-making model of the entropy weight method is built, comprehensively reflecting the accuracy and objectivity of determination of index weights.

"Entropy", proposed by K.Clausius, a German physicist in 1850, is used to express the measurement element of energy failure degree. Shannon C E introduced the idea of Entropy to the theory of information, so as to produce information entropy. In theory of information, entropy is also called the average information, which is a measurement element of information [4]. The method for determining index weight by means of the idea of entropy is called entropy weight method. Entropy weight method is an objective endowment method, which determines the index weight by the use of information provided by index entropy. It starts from reflecting the importance according to the difference between the observed values of the same index. One index of the evaluated object has little influence on the evaluation system if there is little difference between the index data. Entropy weight has a special meaning. It is the relative fierce degree coefficient of indexes in competition when an evaluated object is given and the evaluation index values are determined other than the actual importance coefficient of an index in the evaluation problem. The entropy weight is directly associated with the evaluated object. Entropy weight shall represent the useful information contributed by the index in the problem from the perspective of information [6]. 
It is known from the afore-said content that the corresponding evaluation index has larger amount of information and the index is more important as the entropy is smaller and the entropy weight is bigger, and vice versa. The size of the evaluation index weight can be objectively obtained.

There are several advantages when the entropy weight method is introduced to the index system of the cognitive testability: endowment with the entropy weight method can avoid human disturbance of the evaluation index weights, making the evaluation result more realistic; the calculation of the index entropies can measure the size of the amount of information of indexes, so as to ensure the built index performance reflect the vast majority of original information.

Endowment with entropy weight method is divided into the following three steps:

(1) Normalization of the original data matrix. Assuming the original data matrix with $m_{\text {evaluation indexes and } n \text { evaluation objects as }} A=\left(a_{i j}\right)_{m \times n}$, normalize it and get $R=\left(r_{i j}\right)_{m \times n}$. For the positive index, the normalization formula is:

$$
r_{i j}=\frac{a_{i j}-\min _{j}\left\{a_{i j}\right\}}{\max _{j}\left\{a_{i j}\right\}-\min _{j}\left\{a_{i j}\right\}}
$$

For the negative index, the normalization formula is:

$$
r_{i j}=\frac{\max _{j}\left\{a_{i j}\right\}-a_{i j}}{\max _{j}\left\{a_{i j}\right\}-\min _{j}\left\{a_{i j}\right\}}
$$

(2) Definition of entropy. In an evaluation problem with $m$ evaluated indexes and $n$ evaluated objects, the entropy of $i$ index is

$$
\begin{gathered}
h_{i}=-k \sum_{j=1}^{n} f_{i j} \ln f_{i j} \\
f_{i j}=\frac{r_{i j}}{\sum_{j=1}^{n} r_{i j}}, k=\frac{1}{\ln n} \text { (when } f_{i j}=0, f_{i j} \ln f_{i j}=0 \text { ). }
\end{gathered}
$$

(3) Definition of entropy weight. After the definition of the entropy of $i$ index, the entropy weight of $i$ index can be obtained as follows:

$$
w_{i}=\frac{1-h_{i}}{m-\sum_{i=1}^{m} h_{i}}\left(0 \leq w_{i} \leq 1, \sum_{i=1}^{m} w_{i}=1\right)
$$

\section{Conclusion}

Proposing cognitive testability will have a far-reaching influence on the development of equipment and national defense in the long term. Building the index system and mathematical model of cognitive testability will significantly contribute to the development of cognitive testability. An evaluation model on the information acquisition ability in the index system of cognitive testability was built based on the comprehensive analysis of relations between indexes, and the entropy weight method was proposed to calculate weights of indexes, which is characterized with strong scientific city, rationality and operability. 


\section{References:}

[1] MA Yan-heng,LIU Xin-hai,LI Gang.The Concept and Index Analysis of CognitiveTestability [J]. Journal of Ordnance Engineering College, 2016, 28(4).

[2] LI Gang.Research on the Fault Forecast Method of Electronic Equipments Based on Multi-source Information Fusion [D].Ordnance Engineering College, 2006.

[3] LU Xu.Research on the Construction and Evaluation of Civil-military Integration Equipment Support Strength System [D]. Ordnance Engineering College, 2015.

[4] CHENG Xiao-hui,LIANG Qi-liang,HE Jun-quan.Method for weight decision of WSNs performance indexbased on entropy weight method [J]. Transducer and Microsystem Technologies, 2013, 32(10):44-45.

[5] HE Feng-biao.The Matlab Tmplementation of Comprehensive Evaluation Method [M].Bei Jing:China Social Sciences Press, 2010.

[6] ZHANG Sui,ZHANG Mei,CHI Guotai.The Science and Technology Evaluation Model Based on Entropy Weightand Empirical Research [J].Chinese Journal of Management,2010,7(1):34-42. 